\title{
UJI KEEFEKTIFAN EKSTRAK ALELOPATI AKAR TEKI (Cyperus rotundus L.) DAN BANDOTAN (Ageratum conyzoides L.) TERHADAP PERTUMBUHAN SAWI HIJAU (Brassica rapa L.)
}

The Effectiveness Test Of Root Alelopathic Extract (Cyperus rotundus L.) and Bandotan (Ageratum conyoides L.) On The Growth Of Mustard Greens Plants (Brassica rapa L.)

\author{
Sri Rahayu*, Asri Pirade Paserang dan Wahyu Harso \\ Jurusan Biologi Fakultas Matematika dan IImu Pengetahuan Alam Universitas Tadulako Tondo \\ Palu, Sulawesi Tengah 94118
}

Keywords:

Ageratum conyzoides L, Cyperus rotundus $\mathrm{L}$, Allelopathy, Growth.
Kata Kunci:

Ageratum conyzoides L, Cyperus rotundus L, Alelopati, Pertumbuhan.

\begin{abstract}
Weeds such as Cyperus rotundus L. dan Ageratum conyzoides L. release allelopatic compounds which can inhibit the growth of crops. The aim of this study was to compare the inhibition of allelopatic compounds contained $C$. rotundus $\mathrm{L}$. and $A$. conyzoides root exctract to Brassica rapa L. growth. This study was conducted in a greenhouse and was based on Completely Randomized Design with two factors. The first factor was type of root extracts (extract from either $C$. rotundus root or $A$. conyzoides root) and the second factor was concentration of root extract. Root extract concentrations added to growth medium of $B$. rapa $L$. 10 days after planting were $0,100,300$ and $500 \mathrm{~g} / \mathrm{L}$ respectifely. The addition of root extract was repeated every week until crop harvested. The results showed that there was not significantly different between $C$. rotundus and $A$. conyzoides roots extract to inhibit $B$. rapa growth. Increassing of root extract concentrations from both roots increased inhibition of $B$. rapa growth.
\end{abstract}

\begin{abstract}
ABSTRAK
Gulma seperti Cyperus rotundus L. dan Ageratum conyzoides L. melepaskan senyawa allelopatic yang dapat menghambat pertumbuhan tanaman. Tujuan dari penelitian ini adalah untuk membandingkan penghambatan ekstrak senyawa alelopatik terkandung pada akar $C$. rotundus $\mathrm{L}$. dan $A$. conyzoides terhadap pertumbuhan Brassica rapa L.. Penelitian ini dilakukan di rumah kaca dan didasarkan pada Rancangan Acak Lengkap dengan dua faktor. Faktor pertama adalah jenis ekstrak akar (ekstrak dari akar C. rotundus atau A. conyzoides) dan faktor kedua adalah konsentrasi ekstrak akar. Konsentrasi ekstrak akar ditambahkan ke media pertumbuhan $B$. rapa L. 10 hari setelah tanam adalah $0,100,300$ dan $500 \mathrm{~g} / \mathrm{L}$. Penambahan ekstrak akar diulang setiap minggu sampai panen dipanen. Hasil penelitian menunjukkan bahwa tidak ada perbedaan yang signifikan antara ekstrak akar $C$. rotundus dan $A$. conyzoides untuk menghambat pertumbuhan $B$. rapa. Peningkatan konsentrasi ekstrak akar dari kedua akar meningkatkan penghambatan pertumbuhan $B$. rapa.
\end{abstract}

Corresponding Author : sri.rahayu769@yahoo.com 


\section{PENDAHULUAN}

Alelopati merupakan peristiwa suatu individu tumbuhan menghasilkan zat kimia yang dapat menghambat pertumbuhan jenis tumbuhan lain yang ada atau bersaing dengan tumbuhan tersebut (Odum 1971). Pada umumnya alelopati dikaitkan dengan masalah gangguan yang ditimbulkan oleh tumbuhan pengganggu (gulma) yang tumbuh bersama-sama dengan tanaman pertanian. Selain itu berkaitan pula dengan keracunan yang ditimbulkan akibat penggunaan bahan penutup tanah (mulsa) pada berbagai jenis pertanaman, dengan beberapa jenis rotasi tanaman. Senyawasenyawa alelopati dapat ditemukan pada jaringan tumbuhan (daun, akar, batang, rhizome, bunga, buah dan biji) (Rohman, 2001).

Beberapa gulma yang terbukti memiliki zat alelopati adalah lempuyangan (Agropyron repen L.) teki (Cyperus rotundus L.) rumput grinting (Cynodon dactylon L.) dan alang-alang (Imperata cylindrica L.). Sastroutomo (1990) tumbuhan bandotan ( $A$. conyzoides L.) juga memiliki senyawa alelopati. Gulma-gulma di atas diketahui sangat kompetitif dengan tanaman budi daya dan dapat menyebabkan penurunan pada hasil produksi tumbuhan lain (Setyowati, 2001).

Penanganan herbisa sintetik untuk membasmi gulma memberikan dampak yaitu pencemaran lingkungan, meninggalkan residu pada produk pertanian dan juga mematikan hama (Sutedjo, 1995). Gulma sangat merugikan bagi tanaman budidaya, selain itu gulma juga dapat mengeluarkan zat allelopati yang mengakibatkan sakit atau matinya tanaman pokok (Sembodo, 2010).

Siregar dkk (2017) melaporkan bahwa ekstrak umbi teki dengan konsentrasi yang berbeda-beda berpengaruh nyata terhadap tinggi tumbuhan bayam duri. Sedangkan Hafsah dkk. (2012), melaporkan bahwa konsentrasi $(500 \mathrm{~g} / \mathrm{L})$ bandotan dapat menekan perkecambahan sawi 100\%. Bandotan ( $A$. conyzoides L.) dan teki ( $C$. rotundus L.) digunakan sebagai bahan penelitian karena tumbuhan ini seringkali populasinya lebih dominan dibandingkan tanaman liar lainnya Bandotan $(A$. conyzoides L.) dan teki (C. rotundus L.) digunakan sebagai bahan penelitian karena tumbuhan ini seringkali populasinya lebih dominan dibandingkan tanaman liar lainnya (Tyas, 2003).

Pada suatu agroekosistem, senyawa alelopati kemungkinan dapat dihasilkan oleh gulma, tanaman pangan, dan hortikultura (semusim), tanaman berkayu, residu dari tanaman dan gulma, serta mikroorganisme. Alelopati dari tanaman gulma dapat dikeluarkan dalam bentuk eksudat dari akar dan serbuk sari, keseluruhan organ (decomposition), senyawa yang menguap (volatile) dari daun, batang, dan akar, serta 
melalui pencucian (leaching) dari organ bagian luar (Reigosa et al., 2000).

Berdasarkan uraian di atas, maka perlu dilakukan penelitian mengenai uji keefektivan ekstrak alelopati akar teki (Cyperus rotundus L.) dan bandotan (Ageratum conyzoides L.) terhadap

\section{BAHAN DAN METODE}

Penelitian ini dilakukan dari bulan Januari sampai Februari 2018 yang bertempat di Rumah Plastik dan di Laboraturium Bioteknologi Jurusan Biologi Fakultas Matematika dan IImu Pengetahuan Alam Universitas Tadulako.

\section{Bahan dan Alat}

Alat yang digunakan yaitu Kertas saring, gelas ukur, blender, labu Erlenmeyer, corong, kertas label, gelas plastik, timbangan neraca analitik, aluminium foil, alat tulis dan kamera. Bahan yang dipakai yaitu yaitu, Biji Brassica rapa L. akar Ageratum conyzoides L. akar Cyperus rotundus L. dan pupuk kompos yang merupakan campuran dari tanah dan kotoran hewan.

\section{Prosedur Penelitian}

Penelitian dilakukan dengan menggunakan Rancangan Acak Lengkap dengan dua faktor yaitu faktor pertama adalah ekstrak akar dari akar gulma Ageratum conzyoides (A) Cyperus rotundus (C) dan faktor kedua adalah konsentrasi dari ekstrak akar kedua gulma tersebut (K). pertumbuhan sawi hijau (Brassica rapa L.) agar membandingkan kemampuan senyawa alelopati dari akar teki (Cyperus rotundus L.) dan akar bandotan (Ageratum conyziodes L.) dalam menghambat pertumbuhan tanaman sawi hijau (Brassica rapa L.).

Konsentrasi yang akan diberikan adalah K0 = tanpa pemberian ekstrak akar, K1= 100 $\mathrm{g} / \mathrm{L} ; \mathrm{K} 2=300 \mathrm{~g} / \mathrm{L}$ dan $\mathrm{K} 3=500 \mathrm{~g} / \mathrm{L}$ (Supriati, 2010). Kombinasi dari kedua faktor tersebut menghasilkan 8 unit perlakuan dan masingmasing dari unit perlakuan dilakukan pengulangan sebanyak 4 kali.

Tabel 1. Kombinasi perlakuan pada penelitian ini

\begin{tabular}{ccc}
\hline \multirow{2}{*}{ Konsentrasi } & \multicolumn{2}{c}{ Sumber ekstrak akar } \\
\cline { 2 - 3 } & $\begin{array}{c}\text { Ageratum } \\
\text { conzyoides }\end{array}$ & $\begin{array}{c}\text { Cyperus } \\
\text { rotundus }\end{array}$ \\
\hline $\mathrm{K} 0$ & $\mathrm{~K} 0 \mathrm{~A}$ & $\mathrm{~K} 0 \mathrm{C}$ \\
\hline $\mathrm{K} 1$ & $\mathrm{KIA}$ & $\mathrm{KIC}$ \\
\hline $\mathrm{K} 2$ & $\mathrm{~K} 2 \mathrm{~A}$ & $\mathrm{~K} 2 \mathrm{C}$ \\
\hline $\mathrm{K} 3$ & $\mathrm{~K} 3 \mathrm{~A}$ & $\mathrm{~K} 3 \mathrm{C}$ \\
\hline
\end{tabular}

Keterangan : $\mathrm{K}=$ Konsentrasi

$\mathrm{K} 1=25 \mathrm{~g} / \mathrm{L}$

Ac $=$ Ageratum conyzoides

$\mathrm{K} 2=75 \mathrm{~g} / \mathrm{L}$

$\mathrm{Cr}=$ Cyperus rotundus

$\mathrm{K} 3=125 \mathrm{~g} / \mathrm{L}$

$\mathrm{KO}=0 \mathrm{~g} / \mathrm{L}$

\section{Cara Kerja}

\section{Seleksi biji sawi hijau}

Biji sawi hijau diseleksi dengan cara merendam biji dan melihat keutuhan biji. 
Biji yang tenggelam dan tidak ada kerusakan pada biji akan dipilih sebagai bibit tanaman uji.

\section{Penyemaian benih}

Biji yang telah diseleksi kemudian disemaikan pada media pasir yang sudah dibersihkan. Kelembaban atau kandungan air pada media secara rutin dijaga untuk memastikan bahwa biji akan berkecambah. Setelah semai berumur satu minggu, semai dipilih berdasarkan tingkat keseragaman pertumbuhan sebagai tanaman uji dan kemudian dipindahkan pada media tumbuh. Polybag ukuran $20 \times 30$ yang berisi $3 \mathrm{~kg}$ tanah yang telah dicampur dengan pupuk kandang.

\section{Pembuatan ekstrak dari akar gulma}

Akar Ageratum conyzoides L. dan Cyperus rotundus L. diambil langsung di tempat tumbuhan itu tumbuh. Tumbuhan yang akan di ambil akarnya adalah tumbuhan yang belum berbunga. Akar segar yang telah diambil kemudian dicuci bersih dengan menggunakan air mengalir sampai bersih, selanjutnya aka rteki (C. rotundus L.) dan akar bandotan (A. conyzoides L.) tersebut dipotongpotong sampai berukuran kecil dan dikeringanginkan selama 3 menit. Kedua akar segar tersebut kemudian ditimbang sebanyak (K1) $25 \mathrm{~g}$ (K2) $75 \mathrm{~g}$ (K3) 125 gkemudian diberi aquades sebanyak $250 \mathrm{ml}$ kemudian diblender. Setelah akar diblender lalu disaringdengan menggunakan kertas saring Whatman ukuran $150 \mathrm{~mm}$.

\section{Perlakuan}

Perlakuan pertama yaitu pemberian $50 \mathrm{ml}$ dari larutan ekstrak pada masingmasing perlakuan setelah tanaman berumur 10 hari. Kemudian diulang setiap 7 hari sekali sampai waktu pemanenan. Pemanenan dilakukan pada saat tumbuhan telah berumur 35 hari (5 minggu).

\section{Pemeliharaan}

Pernyiraman dilakukan setiap hari pada pagi hari maupun sore hari sebanyak $100 \mathrm{ml}$ setiap polybag sampai menjelang waktu akhir pengamatan. Penyemprotan dengan insektisida dilakukan kalau memang diperlukan.

\section{Pengamatan}

Perlakuan dihentikan setelah tanaman berumur 35 hari (5 minggu)
a. Tinggi tanaman
b. Berat basah tajuk
c. Berat kering tajuk
d. Berat kering akar

\section{Analisis Data}

Data dianalisis dengan menggunakan twowayANOVA dan diuji lanjut dengan 
Duncan Multiple Range Test pada taraf uji

HASIL

Tinggi Tanaman Sawi (Brassica rapa L)

Tinggi Tanaman sawi umur 35 hari setelah perlakuan pemberian ektrak akar teki dan bandotan.

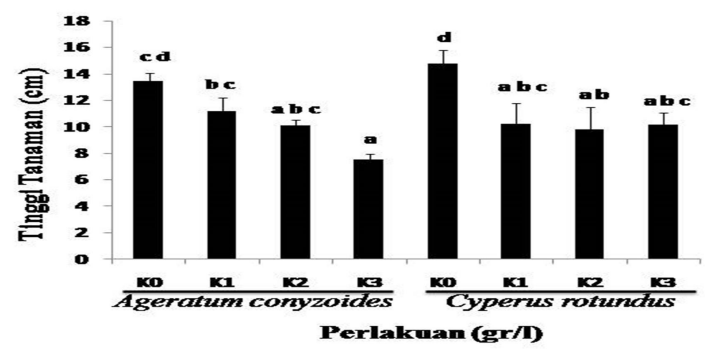

Gambar 1.Tinggi tanaman sawi umur 35 hari setelah diberi ekstrak dari akar teki danekstrak akar bandotan. Ekstrak yang diberikan sebanyak $100 \mathrm{~g} / \mathrm{L}$ (K1), $300 \mathrm{~g} / \mathrm{L}$ (K2), $500 \mathrm{~g} / \mathrm{L}$ (K3) atau tanpa pemberian ekstrak (KO). Nilai pada batang grafik adalah nilai ratarata \pm SD. Batang grafik yang diikuti oleh huruf yang sama menunjukkan tidak berbeda nyata $(P<0,05)$

Berdasarkan hasil analisis semakin tinggi konsentrasi ekstrak yang diberikan semakin menghambat pertambahan tinggi tanaman terutama ekstrak dari akar bandotan pada konsentrasi K3 ( $A$. conyzoides) (Gambar 1). Hasil analisis statistik menunjukkan bahwa ekstrak akar teki dan akar bandotan tidak berbeda nyata dalam menghambat penambahan tinggi tanaman

\section{Berat Basah Tanaman Sawi (Brassica rapa $\mathrm{L}$ )}

$5 \%$ menggunakan software SPSS.

Berat Basah sawi umur 35 hari setelah perlakuan pemberian ektrak akar teki dan bandotan

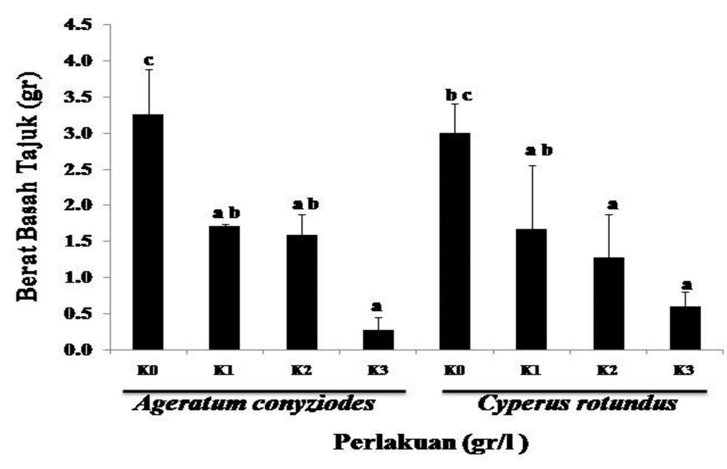

Gambar 2. Berat basah tajuk tanaman sawi umur 35 hari setelah diberi ekstrak dari akar teki dan ekstrak akar bandotan. Ekstrak yang diberikan sebanyak $100 \mathrm{~g} / \mathrm{L}$ (K1), $300 \mathrm{~g} / \mathrm{L}$ (K2), $500 \mathrm{~g} / \mathrm{L}(\mathrm{K} 3)$ atau tanpa pemberian ekstrak (KO). Nilai pada batang grafik adalah nilai rata-rata \pm SD. Batang grafik yang diikuti oleh huruf yang sama menunjukkan tidak berbeda nyata $(P<0,05)$

Berdasarkan Analisis statistik menunjukan, tanaman yang diberi ekstrak akar bandotan dan ekstrak akar teki memiliki berat basah tajuk yang rendah dibandingkan dengan berat basah tajuk pada tanaman yang tidak diberikan ekstrak sama sekali KO (tanpa pemberian ekstrak).

Semakin tinggi konsentrasi ekstrak yang diberikan baik antara ekstrak akar teki dan ekstrak akar bandotan, tanaman sawi cenderung memiliki berat basah tajuk yang lebih rendah meskipun tidak berbeda nyata. Adapun hasil analisis statistik menunjukkan 
bahwa ekstrak dari akar teki lebih menghambat pertambahan berat basah tajuk tanaman dibandingkan dengan ekstrak dari akar bandotan

\section{Berat KeringTajuk Sawi (Brassica rapa}

\section{L.)}

Berat Kering Tajuk sawi umur 35 hari setelah perlakuan pemberian ektrak akar teki dan bandotan.

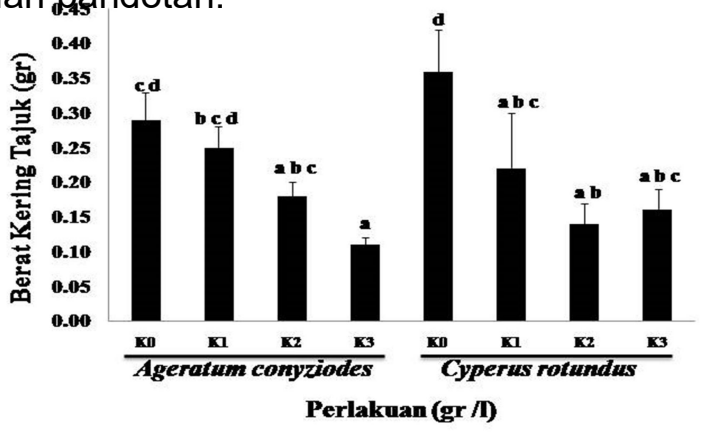

Gambar 3. Berat kering tajuk tanaman sawi umur 35 hari setelah diberi ekstrak dari akar teki dan ekstrak akar bandotan. Ekstrak yang diberikan sebanyak $100 \mathrm{~g} / \mathrm{L} \quad(\mathrm{K} 1), 300 \mathrm{~g} / \mathrm{L}$ (K2), $500 \mathrm{~g} / \mathrm{L}(\mathrm{K} 3)$ atau tanpa pemberian ekstrak (KO). Nilai pada batang grafik adalah nilai rata-rata \pm SD. Batang grafik yang diikuti oleh huruf yang sama menunjukkan tidak berbeda nyata $(P<0,05)$.

Berdasarkan hasil analisis statistik menunjukkan tanaman yang diberikan ekstrak akar teki (Cyperus rotundus L.) dan ekstrak akar bandotan (Ageratum conyzoides L.) pada media tumbuhnya akan memiliki berat kering tajuk yang lebih rendah dibandingkan dengan berat kering tajuk dari tanaman yang tidak diberi ekstrak.

\section{Berat KeringAkar Sawi (Brassica rapa) L)}

Berat Kering Tajuk sawi umur 35 hari setelah perlakuan pemberian ektrak akar teki dan bandotan.

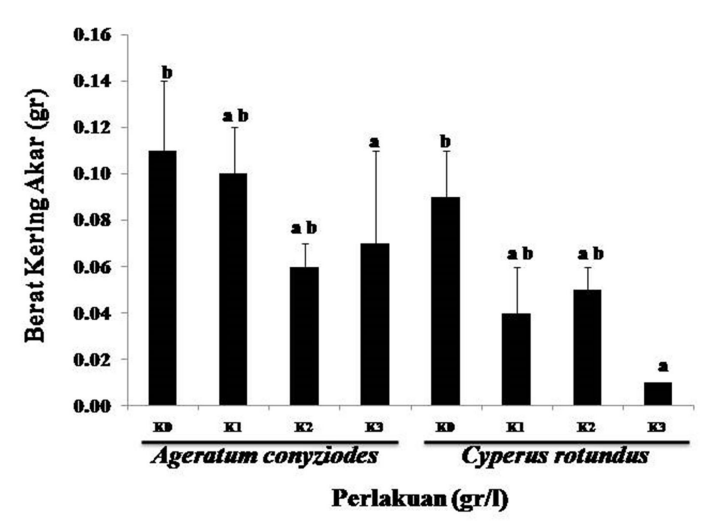

Gambar 4. Berat kering akar tanaman sawi umur 35 hari setelah diberi ekstrak dari akar teki dan ekstrak akar bandotan. Ekstrak yang diberikan sebanyak $100 \mathrm{~g} / \mathrm{L}$ (K1), $300 \mathrm{~g} / \mathrm{L}(\mathrm{K} 2), 500 \mathrm{~g} / \mathrm{L}$ (K3) atau tanpa pemberian ekstrak (KO). Nilai pada batang grafik adalah nilai rata-rata \pm SD. Batang grafik yang diikuti oleh huruf yang sama menunjukkan tidak berbeda nyata $(P<0,05)$.

Berdasarkan Hasil analisis statistik menunjukkan, yakni tanaman sawi yang diberi ekstrak akar teki dan ekstrak bandotan memiliki berat kering akar yang lebih rendah dibandingkan dengan tanaman sawi yang tidak diberikan ekstrak (KO). Semakin tinggi konsentrasi ekstrak yang diberikan, baik dari ekstrak akar bandotan atau ekstrak akar teki,tanaman sawi cenderung akan memiliki berat kering akar yang lebih rendah. 


\section{PEMBAHASAN}

Pada penelitian ini menunjukkan bahwa ekstrak akar teki dan ekstrak akar bandotan dapat menghambat pertumbuhan baik pada tajuk maupun pada akar tanaman sawi (B. rapa L.). Menurut Sukman dan Yakup (1991) bandotan ( $A$. conyzoides L.) merupakan salah satu gulma yang dapat menekan pertumbuhan sawi dan menurut Setyowati (2001) teki (C. rotundus L.) merupakan gulma yang sangat kompetitif dengan tanaman budidaya. Hal ini disebabkan pada kedua gulma mengandung zat alelopati. Alelopati disebabkan oleh senyawa alelokemi yaitu hasil metabolit sekunder yang bersifat racun bagi tanaman dan lingkungan sekitarnya (Sastroutomo, 1999). Patrick (1971) menyatakan bahwa hambatan alelopati dapat berbentuk pengurangan dan kelambatan perkecambahan biji, penghambatan pertumbuhan tanaman, gangguan system perakaran, klorosis, layu, bahkan kematian tanaman.

Senyawa yang terdapat di dalam bandotan antara lain, asam galik, asam koumarin, asam protokatekuin, katekin, asam p-hidroksi benzoat, asam p-koumarin, asam benzoate dan asam sinapin (Xuanet al.,2004). Sementara pada umbi rumput teki mengandung alkaloid sebanyak 0,3-1\%, minyak atsiri sebanyak 0,3-1\%, flavonoid 1$3 \%$ yang isinya bervariasi, tergantung daerah asal tumbuhnya (Achyad dan
Rasyidah, 2000). Sementara Lawal dan Adebola (2009) menyebutkan kandungan kimia rumput teki yaitu alkaloid, flavonoid, tanin, pati, glikosida seskuiterpenoid dan saponin. Tannin dan flavonoid merupakan golongan senyawa fenolik. Menurut Mastuti (2016) senyawa fenolik yang dilepaskan kedalam tanah akan menghambat tumbuhan lain.

Semakin tinggi konsentrasi ekstrak akar teki maupun ekstrak akar bandotan yang diberikan semakin menghambat pertumbuhan tanaman sawi. Hal ini disebabkan semakin banyaknya zat alelopati yang terkandung di dalamnya dalam menghambat pertumbuhan akar. Pertumbuhan akar yang terhambat akan menghambat pertumbuhan tajuk. Togatorop dan Berliana (2010) juga menunjukkan bahwa dengan meningkatnya konsentrasi alelopat dari $20,5 \mathrm{~g} / \mathrm{L}$ hingga $50 \mathrm{~g} / \mathrm{L}$ untuk bandotan alelopat mampu menghambat pertumbuhan akar kecambah. Hal ini menunjukkan bahwa respon penghambatan zat alelopati mulai aktif pada konsentrasi 50 g/L paling menekan pertumbuhan akar kecambah sawi.

Pada penelitian ini tidak ada perbedaan yang nyata antara ekstrak akar teki dan ekstrak akar bandotan dalam menghambat pertumbuhan tanaman sawi. Hal ini mungkin disebabkan oleh respon yang sama dari tanaman sawi terhadap 
alelopati yang dihasilkan oleh akar teki maupun bandotan.

\section{DAFTAR PUSTAKA}

Achyad, D.E. dan Rasyidah, R. (2000), Teki Cyperus rotundusL., PT. Asiamaya.com Indonesia, Jakarta. http://www. asiamaya .com/jamu/isi/tekicyperusrotundus.htm . Diakses pada tanggal 07/03/2018. Pukul 16.07 WIB

Hafsah, S., M. Abdul Ulim., dan Nofayanti. M. C. (2012). Alelopati Ageratum conyzoides L. terhadap pertumbuhan sawi. J. Floratek 8: 18-24.

Lawal. Q.A. and Adebola, O. (2009). Chemical Composition of The EssentialOils of Cyperus rotundus L. Fromsouth Africa. Journal Moleculer, 14, 2909-2917.

Mastuti, R. (2016). Modul 1 Fisiologi Tumbuhan. Metabolit Sekunder dan Pertahanan Tumbuhan. Jurusan Biologi, FMIPA Universitas Brawijaya.

Odum, E. P., (1971). Dasar-Dasar Ekologi. Edisi ketiga Gadjah Mada University Press. Yogyakarta.

Patrick, Z. A. (1971). Phytotoxic substances associated with the decomposition in soil of plant residues. Soil Science, 111 (1),13-18.https: //files.osf. io/v1/ resourc

es/4nzf3/providers/osfstorage/59fa5ffc ?initialWidth=766\&direct=\&mode=ren der.

Reigosa MS, Gonzalezy L, Soute XC et al. (2000). Allelopathy in forest

\section{UCAPAN TERIMAKASIH}

Penulis mengucapkan terima kasih kepada sahabat-sahabat yang telah membantu proses penelitian baik di lapangan dan di laboratorium.

ecosystems, allelopathy in ecological agricultural and forestry. Proceedings III. International Congress Allelopathy in Ecological Agricultural and Forestry. Dhawad, India, 18-21 August, 1998.

Rohman. F. (2001). Petunjuk praktikum ekologi tumbuhan. Universitas Malang.

Sastroutomo. (1999). Ekologi Gulma. Jakarta: Gramedia Pustaka Utama.

Siregar, E., N., Nugroho, A., and Soelistyono, R. (2017). Uji alelopati ekstrak umbi teki pada gulma bayam duri (Amaranthus spinosus L.) dan pertumbuhan tanaman jagungmanis (Zea mays L. Saccharata). Jurnal Produksi Tanaman Vol. 5 No. 2, Februari 2017: 290-298.

Sembodo, D.R.J. (2010). Gulma dan Pengolahannya. Graha IImu. Yogyakarta.

Setyowati. N. (2001). Efikasi alelopati teki formulasi cairan terhadap gulma Mimosa invisa dan Melonchiacprchorifolia. Journal Penelitian Fakultas Pertanian. Universitas Bengkulu.

Sutedjo. M. M. (1995). Pupuk dan Cara Pemupukan. PT. Rineka Cipta. Jakarta.

Tyas, Y R. (2003). Pengaruh keberadaan gulma terhadap hasil produksi jagung manis (Zea mays var. Saccharata). 
Skripsi tidak diterbitkan. Universitas Islam Negeri Malang.

Togatorop, Berliana Rodo. (2010). Analisis Efisiensi Produksi dan Pendapatan Pada Usaha tani Jagung di Kecamatan Wirosari, Kabupaten Grobongan, Skripsi Fakultas Ekonomi Xuan, T. D., N. H. Hong., T. D. Khanh and C. M. Min . (2004). Assessment of phytotoxic action of Ageratum conyzoides L. (billy goat weed) on weeds. Crop Protection 23(10):915922. Universitas Diponegoro, Semarang. 